\title{
EVALUATION OF BIAXIAL FLEXURAL STRENGTH AND TRANSLUCENCY OF MULTICHROMATIC TRANSLUCENT ZIRCONIA AND LITHIUM DISILICATE CERAMICS
}

\author{
Jihad G. Hamed ${ }^{1}$ BDS, Sameer I. Bakry² PhD, Sanaa A. Hussein² PhD, Fayza H. Al \\ Abbassy $^{3} \mathrm{PhD}$
}

\begin{abstract} comparing it with multichromatic high translucency Lithium Disilicate glass-ceramic. repeated measures test. zirconia. of full-contour zirconia restorations made from this material in stress bearing areas.

1-Instructor at the Fixed Prosthodontics Department, Faculty of Dentistry, Alexandria University, Egypt.

2-Professor of Fixed Prosthodontics, Faculty of Dentistry, Alexandria University, Egypt.

3-Professor of Dental Biomaterials, Faculty of Dentistry, Alexandria University, Egypt.
\end{abstract}

INTRODUCTION: Full-contour (monolithic) zirconia restorations are gaining in popularity. High translucent zirconia materials and multilayered zirconia blocks might help to overcome the aesthetic drawbacks of traditional zirconia for fabrication of monolithic restorations OBJECTIVES: Were to evaluate the biaxial flexural strength and translucency of CAD/CAM: multichromatic ultra-translucent zirconia and

MATERIALS AND METHODS40 ceramic specimens were divided into two main groups; Group I: CAD/CAM multichromatic ultratranslucent Zirconia( UTML KATANA Zirconia) \& Group II: Pressable multichromatic high translucent Lithium Disilicate glass-ceramic (e.max press multi). Each group was subdivided into two sub groups; sub group A: disc specimens (12mm diameter $\times 1.5 \mathrm{~mm}$ thickness) were fabricated $(\mathrm{n}=10)$ \& thermocycled $\left(500\right.$ cycles, $5^{\circ} / 55^{\circ} \mathrm{C}, 15 \mathrm{sec}$ dwell time).Then, biaxial flexural strength was measured in MPa. Sub group $B$ : rectangular specimens $(12 \mathrm{~mm}$ length $\times 10 \mathrm{~mm}$ width $\times 1.5 \mathrm{~mm}$ thickness $)$ were fabricated $(\mathrm{n}=10)$. Spectrophotometric analysis was conducted to evaluate and compare the degree of translucency by translucency parameter (TP). Data were analyzed using student t-test \& ANOVA with

RESULTS Statistical analysis of Biaxial flexural strength using student t-test revealed that group I (607.24 \pm 71.79 ) showed higher statistically significant biaxial flexural strength values than group II $(290.69 \pm 41.19)(\mathrm{p}<0.001 *)$. Results of translucency revealed that there were significant statistical differences between the two subgroups where IPS e.max Press Multi provided better translucency than UTML KATANA

CONCLUSIONS: Multi layered zirconia showed higher mechanical, but lower optical properties than lithium disilicate. The multi layered zirconia showed four layers with different light transmittance capabilities. It might therefore be useful for enhancing the aesthetic appearance

KEYWORDS: Biaxial flexural strength, Translucency, Multichromatic zirconia, Translucent zirconia, lithium disilicate ceramics.

\section{INTRODUCTION}

Metal-ceramic restorations have been widely used in dentistry due to their capacity to provide high strength, longevity and acceptable aesthetics. All-ceramic restorations have gained acceptance among clinicians and patients due to their superior esthetics, the possibility of conservative tooth preparations, excellent biocompatibility and superior optical properties $(1,2)$.

Among a variety of ceramic materials, partially stabilized zirconia has proven to offer enhanced mechanical properties compared to all other all-ceramic materials due to its transformation toughening mechanism (3).

Despite the advantages of zirconia as it is stronger and tougher than most other ceramics used in dentistry, one of the major drawbacks of zirconia is its opaqueness. That is why it should be veneered with lower strength esthetic porcelain; however the chipping and fracturing of veneering porcelains applied to zirconia substructures remains problematic (4).

Zirconia shows a flexural strength of 1,000 MPa., while the typical veneering porcelains exhibit 50-120 MPa. Thus, failure rates of $15 \%$ of the veneering porcelain have been reported after 2 years (5).

ne approach to overcome chipping is to produce fullcontour monolithic zirconia fixed dental prostheses (FDPs) without veneering porcelain. The major clinical advantage of monolithic zirconia restorations is the significantly reduced material thickness in comparison to veneered restorations or other monolithic ceramics (6).

The major problem of monolithic zirconia is that, their optical behavior is still considered controversial. Zirconia is a monochromatic and opaque material, which is a clinical drawback in terms of aesthetics, so it is indicated to restore posterior teeth and its use is limited in the anterior region (7).

Translucent zirconia has been introduced for more aesthetic all-ceramic restorations than conventional fullcontour zirconia restorations offer. The manufacturers claimed that these ceramics have the same translucency as lithium disilicate (8).

Recently a multichromatic or multi-Layered (ML) zirconia Disc (KATANA ${ }^{\mathrm{TM}}$ Zirconia) has been introduced for more aesthetic all-ceramic restorations than monochromatic full-contour translucent zirconia restorations trying to imitate the appearance of layered porcelain in a full-contour monolithic restoration (9). It is ideally suited for use in the anterior region; the manufacturer recommended its use for single crowns, inlays, onlays, veneers and 3-unit bridges.

According to the manufacturer, both chroma and translucency are graduated from the incisal to the cervical region in the translucent multilayered blocks with less 
translucency in the cervical, this chromatic graduation reproduces the enamel and dentin shades (10).

Therefore, the null hypothesis of this study stated that translucency \& flexural strength of monolithic multilayered high translucent zirconia materials are comparable with multichromatic high-translucent Lithium Disilicate glass-ceramic without significant difference.

\section{MATERIALS AND METHODS}

In the present study, two different types of ceramic materials, one CAD/CAM zirconia based (UTML KATANA ZIRCONIA) and pressable Lithium Disilicate glass-ceramic (IPS e.max Press Multi) were tested with respect to their biaxial flexural strength after thermocycling and translucency using (TP).

Ultra Translucent Multi Layered disc of KATANA ZIRCONIA (UTML) shade A2 was selected (Figure 1).
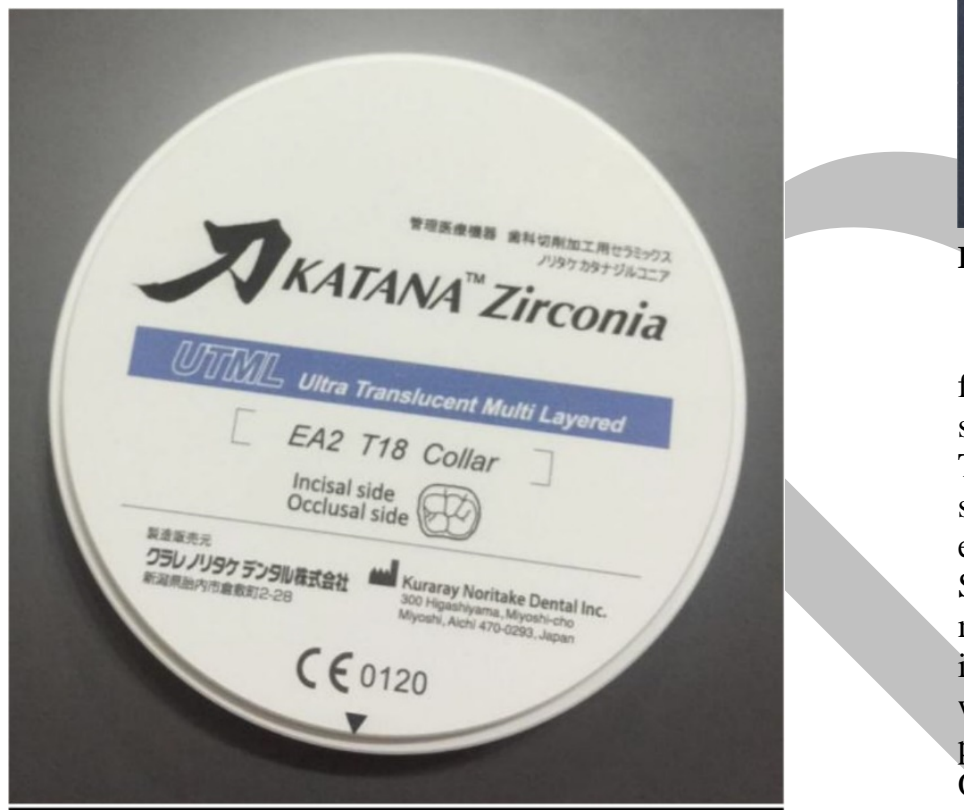

Fig.1: Showing shade A2 UTML KATANA ZIRCONIA disc.

Disc thickness $18 \mathrm{~mm}$ was selected as the maximum specimen length was $12 \mathrm{~mm}$. Ten disc specimens $(12 \mathrm{~mm}$ diameter $\times 1.5 \mathrm{~mm}$ thickness) were fabricated according to manufacturer's instruction for biaxial flexural strength test (12). Ten rectangular specimens (12mm length $\times 10 \mathrm{~mm}$ width $\times 1.5 \mathrm{~mm}$ thickness) were fabricated according to manufacturer's instruction for spectrophotometric analysis. The UTML katana specimens were designed in CAD software (Dentalwings Inc., Montreal, Quebec, Canada) of the system according to desired dimensions. Precolored discs were milled with CAD/CAM system (DWX-50N, Noritake Dental, Aichi, Japan) at presintered stage. Sintering process was performed according to manufacturer's instructions in MV MIHM-Vogt HT sintering furnace. Then one side of each specimen was polished by a single experienced operator using a straight lab handpiece (K5plus, Kavo,Germany) connected to an electrical control unit (K-control4960, Kavo, Germany) with diamond polishers (Zircpol Plusand Zircoshine Plus, Diatech, Switzerland) followed by a polishing paste (Zircon-Brite; Dental Ventures of America Inc.,Corona, CA, USA) at a constant speed of 10,000 rpm under constant pressure and standard time in a single directed motion, following manufacturers' instructions . Glazing was performed following manufacturers' instructions using CERABIENTM ZR "FL Glaze”. After sintering\& glazing, the thicknesses of the specimens were checked with the digital caliper.

For the fabrication of IPS e.max press multi specimens; Prepon (inlay wax) was used to fabricate wax specimens. A split copper mold was used to fabricate the wax specimens (with one circular hole of $12 \mathrm{~mm}$ diameter $\times 1.5 \mathrm{~mm}$ thickness and one rectangular space of $12 \mathrm{~mm}$ length $\times 10 \mathrm{~mm}$ width $\times 1.5 \mathrm{~mm}$ thickness) (Figure 2 ).

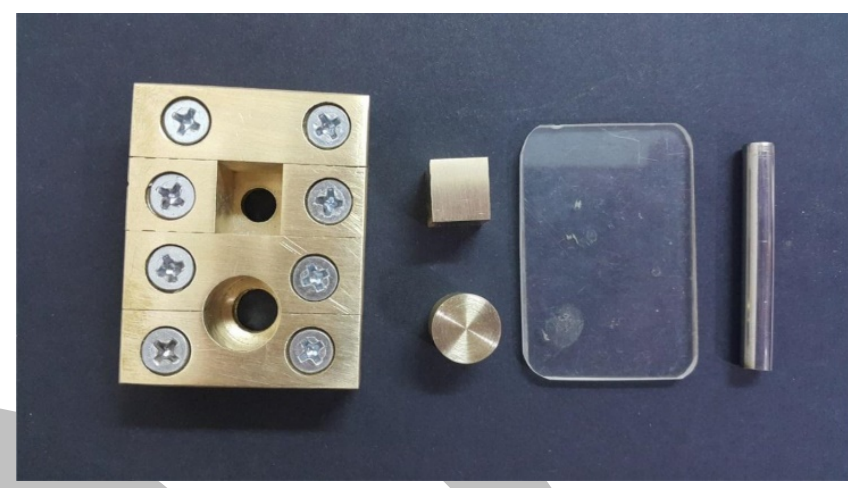

Fig.2: Split copper mold for fabricating wax specimens.

Ten circular wax discs were fabricated for biaxial flexural strength test (12) and ten rectangular wax specimens were fabricated for spectrophotometric analysis. The wax specimens were attached to the sprues so that smooth flowing of the viscous ceramic during pressing was enabled. 200g IPS investment ring system was selected. Spruing and investing were done following the manufacturer's instructions. The IPS e.max Press Multi ingot, IPS Alox Plunger and IPS Multi One-Way Plunger were not preheated. Patented "horizontal pressing" procedure was used; using IPS Alox Plunger and IPS Multi One-Way Plunger. The investment ring was removed from the preheating furnace immediately after the preheating cycle had been completed \& the cold IPS e.max press Multi ingot was placed into the hot investment ring with the imprinted side facing up. Next, the one-way plunger was placed with the rounded side facing down, followed by the Alox plunger. The assembled ring was loaded into the press furnace. The IPS e.max Press Multi program was selected \& started using Ivoclar Vivadent's Programat EP 3010 pressing furnace. After the end of the pressing cycle, the investment ring was removed from the press furnace using the investment ring tongs immediately after pressing. The investment ring was placed on a cooling grid to cool down. Divesting and removing the reaction layer were done following the manufacturer's instructions. Then, the thicknesses of the specimens were checked with the digital caliper. The glazing material was applied in an evenly covering layer on one aspect of each specimen in the usual manner according to the manufacturer instructions.

This study was conducted on two parallel groups: Group (I): CAD/CAM UTML KATANA Zirconia which was divided into two subgroups. Sub group IA (ten disc specimens for biaxial flexural strength test) and Sub group IIB: ten rectangular specimens for spectrophotometric analysis. Group (II): multichromatic high translucent Lithium Disilicate glass-ceramic (e.max. press Multi) which was divided into two subgroups. Sub group IIA (ten 
disc specimens for biaxial flexural strength test) and sub group IIB (ten rectangular specimens for spectrophotometric analysis).

Ball on ring test was used for the biaxial flexural strength test. Disc specimens of sub group IA and sub group IIA were thermocycled firstly at 500 cycles in water bathes at temperature range between $5^{\circ} \mathrm{C}$ and $55^{\circ} \mathrm{C}$ for 60 seconds with a dwell time of 12 seconds to represent approximately 6 months of clinical use (11).

A specially designed jig was fixed to the lower plate of universal testing machine (Instron, Comten Industries Inc; U.S.A), in which each disc from the previously mentioned subgroups was centrally placed on a circular $10 \mathrm{~mm}$ diameter knife-edge support and the load was applied centrally at a rate of $1 \mathrm{~mm} \backslash$ minute with a spherical indentor of $5 \mathrm{~mm}$ (12) until fracture was recorded (Figure 3).

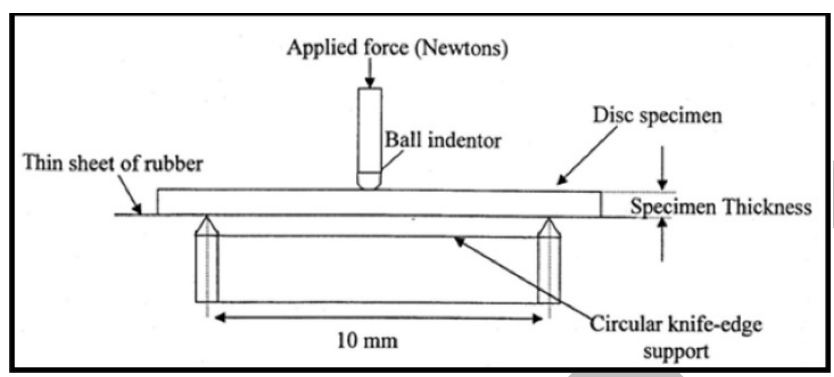

Fig.3: Cross-sectional diagram for the "ball on ring” BFS test

During testing, all the specimens were placed with the glazed surface facing upward toward the indentor and a thin sheet of rubber was placed between the disc and the knife-edge support to accommodate slight irregularities in the disc(12)(Figure 4).

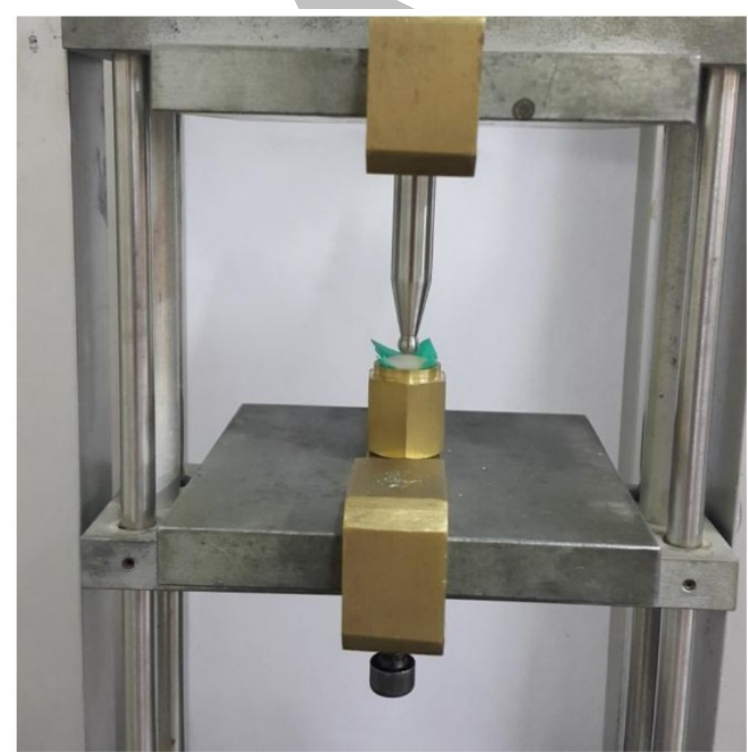

Fig.4: Biaxial flexural strength test using universal testing machine.

A wet piece of filter paper was placed onto the rubber support to maintain the surface of the samples exposed to moisture on the unglazed surface under test.

The bi-axial flexure strength of Mono-block fabricated discs will be calculated according to the equation of Timoshenko and Woinowsky-Krieger (13). $\sigma \max =\mathrm{p} / \mathrm{h} 2\{(1+\mathrm{v})[0.485 \times 1 \mathrm{n}(\mathrm{a} / \mathrm{h})+0.53]+0.48\}$

Where: omax is the maximum tensile stress

$\mathrm{P}$ is the measured load at fracture

$\mathrm{a}$ is the radius of the knife-edge support

$\mathrm{v}$ is the Poisson's ratio for the material

(a value of 0.25 was substituted for porcelain)

$\mathrm{h}$ is the specimen thickness measured with the digital micrometer

$1 \mathrm{n}$ is the natural logarithm.

The number of specimen fragments produced on loading the ceramic discs under bi-axial flexural strength conditions was recorded as an assumption about the amount as well as the radiation of cracks that developed during firing of the ceramic material and/or following thermocycling. Statistical analysis of biaxial flexural strength and number of fractured fragments was done using student t-test.

The twenty rectangular specimens of the two groups were used to evaluate the translucency. Prior to translucency measurements, thickness of the specimens was checked with a digital caliper then the specimens were ultrasonically cleaned in distilled water for 10 minutes, and dried with compressed air. Then each specimen of both materials was divided into four equal quadrants using an endodontic ruler and a pencil from Q1 representing the cervical quadrant to Q4 representing the incisal one and Q2 and Q3 in between. Translucency was evaluated with (TP) (14) at each quadrant of the multilayered specimen, then the average of translucency of each material was calculated using Spectrophotometer VITA Easyshade @ Advance for analyzing the light transmission. Calibration was performed by placing the probe tip on the calibration port aperture before each specimen measurements. "Tooth single" mode was selected. The rectangular specimens were placed over white $\left(\mathrm{L}^{*}=96.3, \mathrm{a}^{*}=0.1, \mathrm{~b}^{*}=1.9\right)$ and black $\left(\mathrm{L}^{*}=8.9\right.$, $\left.a^{*}=-0.7, b^{*}=1.2\right)$ tiles while placing the glazed surface upward. . The color was evaluated according to the color system CIE $\mathrm{L}^{*} \mathrm{a} \mathrm{b}^{*}$, three times for each quarter corresponding to the four zones of multilayered specimens on each background .The $\mathrm{L}^{*}, \mathrm{a}^{*}$ and $\mathrm{b}^{*}$ values were recorded, the data was gathered and the mean CIE L*a*b* values were recorded for both backgrounds.

The (TP) was calculated using the following equation:

$\mathrm{TP}=[(\mathrm{L} * \mathrm{~B}-\mathrm{L} * \mathrm{~W}) 2+(\mathrm{a} * \mathrm{~B}-\mathrm{a} * \mathrm{~W}) 2+(\mathrm{b} * \mathrm{~B}-\mathrm{b} * \mathrm{~W}) 2] 1 / 2(14)$

Where: $\mathrm{TP}=$ Translucency parameter

$\mathrm{L} * \mathrm{~B}=$ mean $\mathrm{L}^{*}$ value recorded when the ceramic material was on black back ground.

$\mathrm{L} * \mathrm{~W}=$ mean $\mathrm{L}^{*}$ value recorded when the ceramic material was on white back ground.

$\mathrm{a} * \mathrm{~B}=$ mean $\mathrm{a}^{*}$ value recorded when the ceramic material was on black back ground.

$\mathrm{a} * \mathrm{~W}=$ mean $\mathrm{a}^{*}$ value recorded when the ceramic material was on white back ground.

$\mathrm{b} * \mathrm{~B}=$ mean $\mathrm{b}^{*}$ value recorded when the ceramic material was on black back ground.

$\mathrm{b} * \mathrm{~W}=$ mean $\mathrm{b}^{*}$ value recorded when the ceramic material was on white back ground.

If the material is absolutely opaque, TP value is zero; if the material is totally transparent, TP value is 100.The greater the TP value, the higher the translucency of the material.

\section{Statistical analysis}

Statistical analysis of biaxial flexural strength and number of fractured fragments was done using student t-test. 
Statistical analysis of translucency was done using ANOVA with repeated measures \& Student t-test.

\section{RESULTS}

Measurements of Biaxial flexural strength in MPa revealed that highest value $(751.40 \pm 71.79 \mathrm{MPa})$ was observed with group I (CAD/CAM UTML KATANA ZIRCONIA), while the lowest value $(227.27 \pm 41.19 \mathrm{MPa})$ was observed with group II (IPS e.max Press Multi). For group I; A range of value was obtained, that varied from $498.90 \mathrm{MPa}$ to 751.40 $\mathrm{MPa}$ with a mean value of $607.24 \mathrm{MPa}$, and standard deviation of 71.79. For group II; A range of value was obtained, that varied from 227.27 MPa to 366.20 MPa with a mean value of $290.69 \mathrm{MPa}$, and standard deviation of 41.19. Statistical analysis of Biaxial flexural strength using student t-test revealed that group I had a statistically significant higher biaxial flexural strength values (607.24 \pm $71.79)$ than those observed in group II $(290.69 \pm 41.19)$ at $\mathrm{p}$ $\leq 0.05\left(\mathrm{t}=12.095^{*}, \mathrm{p}<0.001^{*}\right)$ as showed in (Table 1$)$.

Table 1: Showing biaxial flexural strength (MPa) comparison between UTML Katana zirconia and e.max Press Multi.

\begin{tabular}{|c|c|c|c|c|}
\hline $\begin{array}{l}\text { Biaxial } \\
\text { flexural } \\
\text { strength }\end{array}$ & $\begin{array}{l}\text { UTML } \\
\text { Katana } \\
\text { zirconia } \\
(\mathrm{n}=10)\end{array}$ & $\begin{array}{c}\text { e.max } \\
\text { Press } \\
\text { Multi } \\
(\mathrm{n}=10)\end{array}$ & $\mathrm{t}$ & $\mathrm{P}$ \\
\hline $\begin{array}{l}\text { Min. - } \\
\text { Max. }\end{array}$ & $\begin{array}{r}498.90- \\
751.40\end{array}$ & $\begin{array}{r}227.27- \\
366.20\end{array}$ & \multirow{2}{*}{$12.095^{*}$} & \multirow{2}{*}{$<0.001^{*}$} \\
\hline $\begin{array}{c}\text { Mean } \pm \\
\text { SD. }\end{array}$ & $\begin{array}{c}607.24 \pm \\
71.79\end{array}$ & $\begin{array}{c}290.69 \pm \\
41.19\end{array}$ & & \\
\hline
\end{tabular}

t, p: $t$ and $p$ values for Student t-test for comparing between UTML Katana zirconia and e.max Press Multi

*: Statistically significant at $\mathrm{p} \leq 0.05$

Statistical analysis of the number of fractured fragments using student t-test revealed that there was no significant statistical differences at $\mathrm{p} \leq 0.05(\mathrm{t}=0.0$, $\mathrm{p}$ $=1.000$ ) between the two groups as showed in (Table 2).

Results of Translucency revealed that; highest TP value $(14.03 \pm 1.36)$ was observed with the group II in Q4 (Incisal quadrant), while the lowest value $(9.84 \pm 0.92)$ was observed with the group I in Q1 (Cervical quadrant) as shown in (Table 3).

Table 2: Showing number of fractured parts (pieces) comparison between UTML Katana zirconia and e.max Press Multi.

\begin{tabular}{|l|c|c|c|c||}
\hline & $\begin{array}{c}\text { UTML } \\
\text { Katana } \\
\text { zirconia } \\
(\mathbf{n}=\mathbf{1 0})\end{array}$ & $\begin{array}{c}\text { e.max Press } \\
\text { Multi } \\
(\mathbf{n}=\mathbf{1 0})\end{array}$ & $\mathbf{T}$ & $\mathbf{p}$ \\
\hline $\begin{array}{l}\text { No of fractured } \\
\text { parts (pieces) }\end{array}$ & & & & \\
Min. - Max. & $3.0-5.0$ & $3.0-6.0$ & 0.0 & 1.000 \\
Mean \pm SD. & $4.1 \pm 0.7$ & $4.1 \pm 1.1$ & \\
\hline
\end{tabular}

$\mathrm{t}, \mathrm{p}$ : $\mathrm{t}$ and $\mathrm{p}$ values for Student t-test for comparing between UTML Katana zirconia and e.max Press Multi.

Table 3: Showing translucency parameter (TP) comparison between UTML Katana zirconia and e.max Press Multi.

\begin{tabular}{|l|c|c|c|c|}
\hline & $\begin{array}{c}\text { UTML } \\
\text { Katana }\end{array}$ & $\begin{array}{c}\text { e.max } \\
\text { Press }\end{array}$ & $\mathbf{T}$ & $\mathbf{P}$ \\
\hline
\end{tabular}

\begin{tabular}{|c|c|c|c|c|}
\hline & $\begin{array}{l}\text { zirconia } \\
(\mathrm{n}=10)\end{array}$ & $\begin{array}{c}\text { Multi } \\
(n=10)\end{array}$ & & \\
\hline \multicolumn{5}{|l|}{ Q1 } \\
\hline $\begin{array}{l}\text { Min. - } \\
\text { Max. }\end{array}$ & $9.0-12.30$ & $\begin{array}{c}10.50- \\
18.10\end{array}$ & \multirow{2}{*}{$3.061^{*}$} & \multirow{2}{*}{$0.007^{*}$} \\
\hline $\begin{array}{c}\text { Mean } \pm \\
\text { SD. }\end{array}$ & $9.84 \pm 0.92$ & $\begin{array}{c}12.23 \pm \\
2.29\end{array}$ & & \\
\hline \multicolumn{5}{|l|}{ Q2 } \\
\hline $\begin{array}{l}\text { Min. - } \\
\text { Max. }\end{array}$ & $\begin{array}{l}9.70- \\
10.60\end{array}$ & $\begin{array}{c}10.80- \\
13.40\end{array}$ & \multirow{2}{*}{$9.365^{*}$} & \multirow{2}{*}{$<0.001^{*}$} \\
\hline $\begin{array}{c}\text { Mean } \pm \\
\text { SD. }\end{array}$ & $9.91 \pm 0.34$ & $\begin{array}{c}12.37 \pm \\
0.76\end{array}$ & & \\
\hline \multicolumn{5}{|l|}{ Q3 } \\
\hline $\begin{array}{l}\text { Min. - } \\
\text { Max. }\end{array}$ & $9.20-12.0$ & $\begin{array}{c}11.90- \\
14.20\end{array}$ & \multirow{2}{*}{$6.804^{*}$} & \multirow{2}{*}{$<0.001^{*}$} \\
\hline $\begin{array}{c}\text { Mean } \pm \\
\text { SD. }\end{array}$ & $\begin{array}{c}10.30 \pm \\
0.81\end{array}$ & $\begin{array}{c}12.76 \pm \\
0.80\end{array}$ & & \\
\hline \multicolumn{5}{|l|}{ Q4 } \\
\hline $\begin{array}{l}\text { Min. - } \\
\text { Max. }\end{array}$ & $9.80-14.0$ & $\begin{array}{l}12.0- \\
16.50\end{array}$ & \multirow{2}{*}{$4.984^{*}$} & \multirow{2}{*}{$<0.001^{*}$} \\
\hline $\begin{array}{l}\text { Mean } \pm \\
\text { SD. }\end{array}$ & $\begin{array}{c}11.16 \pm \\
1.22\end{array}$ & $\begin{array}{c}14.03 \pm \\
1.36\end{array}$ & & \\
\hline $\mathrm{p}_{1}$ & $0.021^{*}$ & $0.020^{*}$ & & \\
\hline \multicolumn{5}{|l|}{ Average } \\
\hline $\begin{array}{l}\text { Min. - } \\
\text { Max. }\end{array}$ & $\begin{array}{l}9.58- \\
11.08\end{array}$ & $\begin{array}{c}11.70- \\
14.63\end{array}$ & \multirow{2}{*}{$8.202^{*}$} & \multirow{2}{*}{$<0.001^{*}$} \\
\hline $\begin{array}{c}\text { Mean } \pm \\
\text { SD. }\end{array}$ & $\begin{array}{c}10.30 \pm \\
0.44\end{array}$ & $\begin{array}{c}12.85 \pm \\
0.88\end{array}$ & & \\
\hline
\end{tabular}

$\mathrm{t}, \mathrm{p}: \mathrm{t}$ and $\mathrm{p}$ values for Student t-test for comparing between UTML Katana zirconia and e.max Press Multi.

$\mathrm{p}_{1}$ : $\mathrm{p}$ value for ANOVA with repeated measures test for comparing between four quadrants.

*: Statistically significant at $\mathrm{p} \leq 0.05$.

The statistical analysis for TP values using student t-test test for comparing between the two materials revealed that: Group II showed a significantly higher TP values than group I in the four quadrants. Group II showed a significantly higher average of $\mathrm{TP}$ value of the four quadrants than group I with $\mathrm{p}<0.001^{*}$, as showed in (Table 3).

The statistical analysis using ANOVA with repeated measures test for comparing between the four quadrants for each group separately revealed that: for group I There were significant statistical differences of TP values between the four quadrant at $\mathrm{p} \leq 0.05$ ( $\mathrm{P} 1=0.021 *)$. For group II; There were also significant statistical differences of TP values between the four quadrant at $\mathrm{p} \leq 0.05$ $(\mathrm{P} 1=0.020 *)$.

\section{DISCUSSION}

Flexural strength and translucency between the two groups showed statistically significant differences, therefore the null hypotheses has been rejected. Although in a gradational multilayered zirconia blank each layer showed a different light transmittance. 
Biaxial flexural testing was selected because it is recognized as a reliable technique and method of choice (ISO 6872) (15), for studying brittle materials since the maximum tensile stress occur within the central loading area and edges failures are eliminated.

A recent systematic review found high survival rate for lithium disilicate single crowns (the 5-year cumulative survival rate: 97.8\%) Pieger et al. (16). In addition, since IPS e.max press Multi could be used in a monolithic form as well as monolithic multichromatic zirconia crowns, they were selected in this study. Two types of production technique for lithium disilicate restorations are commercially available, one for press technique and the other for CAD/CAM (e.g. IPS e.max press and IPS e.max CAD). Since IPS e.max press possesses higher flexural strength (400 $\pm 40 \mathrm{MPa}$ ) than IPS e.max CAD CAD (360 \pm $60 \mathrm{MPa}$ ) according to the manufacturer's data, the former was used in the present study.

On comparing the two tested materials, results revealed that UTML KATANA ZIRCONIA group had a statistically significant higher biaxial flexural strength values (607.24 \pm 71.79$)$ than those observed in IPS e.max Press Multi group (290.69 \pm 41.19). Many studies contributed the strength of IPS e.max press ceramic material to its microstructure as Borges et al. (17). It has an unusual microstructure, in that it consists of many small interlocking plate-like crystals that are randomly oriented. This is ideal from the point of view of strength because the needle-like crystals cause cracks to deflect, branch or blunt; thus, the propagation of cracks through this material is arrested by the lithium disilicate crystals, providing a substantial increase in the flexural strength.

Mechanical behavior of zirconia is strongly dependent on its grain size, and hence its ability to undergo $\mathrm{t}-\mathrm{m}$ transformation. The flexural strength of Y-TZP (900$1400 \mathrm{MPa}$ ), is superior as compared to other dental ceramics, and far above the yield strength of metallic alloys used in dentistry (18).

Results of the present study is in agreement with Piconi and Maccauro (19) who stated that; zirconia has higher flexural strength (>1000 MPa) than lithium disilicate (about $400 \mathrm{MPa}$ ) \& Kang et al. (20) who stated; the fracture resistance of monolithic zirconia molar crowns may be acceptable even at a reduced thickness. Still, there are few available data regarding the matter.

Johansson et al. (21) compared fracture resistance of monolithic zirconia and monolithic lithium disilicate (IPS e.max press) after thermal and mechanical cycling. They reported higher strength for the zirconia crowns compared to lithium disilicate crowns with the same occlusal thickness $(\geq 1.8 \mathrm{~mm}$ ) which supports the results of the current study.

In the same issue, Matsuzaki et al. (22) found that monolithic translucent TZP has the same level of strength as opaque TZP, and the strength decreases as the thickness of veneering porcelain increases. Therefore, it is suggested that colored translucent TZP is clinically useful when used as monolithic restorations.

Results of the current study results show similarity to results of Church et al. (23) who found that; the flexural strengths of the zirconia materials were similar to each other and significantly greater than that of IPS e.max CAD HT. Also with Carrabba et al. (24) who found that; there was an inverse relationship between strength and translucency for three different compositions of Partially Stabilized Zirconia (PSZ) (Aadva ST (standard translucency - ST group), Aadva EI (Enamel Intensive - EI group) and Aadva NT (natural translucent - NT group) \& a reinforced glass ceramic as the Lithium Disilicate LD. Addition of Al2O3 and increasing yttria content strongly influence mechanical and optical properties of Y-TZP ceramics which will affect their clinical indications. The NT zirconia has a significant higher translucency than the other zirconia materials tested but moreover significantly lower compared to LD. Also NT has a lower flexural strength that limits its clinical indication up to three unit FPDs (ISO 6872:2015).

Concerning the mode of fracture for both materials, results of the present study revealed that there was no significant statistical difference at $\mathrm{p} \leq 0.05(\mathrm{t}=0.0, \mathrm{p}$ $=1.000$ ) between the two groups. IPS e.max Press Multi showed slightly higher fragment number than those observed in UTML KATANA ZIRCONIA group, as IPS e.max Press Multi showed that $70 \%$ of the fragments were five or six, while UTML KATANA ZIRCONIA showed that $40 \%$ of the fragments were five. This may be due the fact that both groups were monolithic so that, monolithic specimens may limit the amounts of defects that is why the failure mode was the same.

For IPS e.max Press Multi; the elongated, intermixed and needle-like lithium disilicate crystals embedded homogenously in the glassy matrix of the pressed ceramic material would act as interlocking structure, which could prevent or decrease crack propagation and therefore enhance the flexural strength and fracture toughness (17).

For UTML KATANA ZIRCONIA; the lower fragment number is due to the high strength of zirconia. In zirconia-toughened ceramics with the tetragonal grain size and stabilizer content properly tuned, the stress concentration at the tip of the crack constitutes an energy source able to trigger the transformation of the tetragonal lattice into the monoclinic one. The $\mathrm{t} \rightarrow \mathrm{m}$ transformation that takes place in the material zone ahead of the crack tip (the so-called 'process zone') dissipates part of the elastic energy that promotes progression of the crack (25).

The results in this study regarding color parameters $L^{*}$, a* and $b^{*}$ over black and white backgrounds revealed that there was significant change with increasing of $\mathrm{L}^{*}, \mathrm{a}^{*}$ and $\mathrm{b}^{*}$ with white background for both groups in the four quadrants.

On comparing color parameters $\mathrm{L}^{*}, \mathrm{a}^{*}$ and $\mathrm{b}^{*}$ between the four quadrants over black background and over white backgrounds, results revealed that; for both groups there were significant statistical differences with increasing $\mathrm{L}^{*}$ value toward the incisal (Q4) quadrant \& increasing a* and $b^{*}$ values toward the cervical (Q1) quadrant for both backgrounds. The cause of change in color parameters $\mathrm{a}^{*}$, $\mathrm{b}^{*}, \mathrm{~L}^{*}$, producing differences in $\Delta \mathrm{E}^{*}$ values over black \& white backgrounds is basically due to the reflection of the background color, and this may be due to optical properties (translucency). The change in color parameters within each specimen among the four quadrants is attributed to the difference of transmittance \& slight change in translucency between the layers of the material (26).

This is in agreement with Lee et al. (27) who stated that; discrepancy in color reproduction might have been caused by the difference in translucency of all-ceramic core and veneer ceramics and shade guide tabs, background, and layering scheme. 
Results of Translucency using (TP) when comparing the two tested materials revealed that; there were significant statistical differences between the two materials in the four quadrants with the highest TP value for IPS e.max press Multi (14.03 \pm 1.36$)$ in Q4(Incisal quadrant) \& the lowest TP value for UTML KATANA zirconia (9.84 \pm 0.92) in Q1(Cervical quadrant).

For UTML KATANA zirconia, On comparing TP among the 4 quadrants, results revealed that; there were significant statistical differences between the four quadrant with increasing the TP value from Q1(Cervical quadrant) (9.84 \pm 0.92$)$ to Q4(Incisal quadrant) (11.16 \pm 1.22 ).

For IPS e.max press Multi, On comparing TP among the 4 quadrants, results revealed that; there were significant statistical differences between the four quadrant with increasing the TP value from Q1(Cervical quadrant) (12.23 \pm 2.29 ) to Q4(Incisal quadrant) (14.03 \pm 1.36 ).

Lithium disilicate glass ceramic specimens showed higher translucency compared to monolithic UTML KATANA zirconia of the corresponding shade. This is due to the optical compatibility between the glassy matrix and the crystalline phase, which minimizes internal scattering of the light as it passes through the material (28). IPS system was preferred in this study for comparison since it may be a good alternate to zirconia ceramics in esthetic regions so that, IPS e.max press Multi ingot of the system was chosen. The TP value of human dentin with a thickness of $1.0 \mathrm{~mm}$ has been determined to be 16.4 and that of human enamel 18.1 values similar to those for glass ceramics (TP ranged from 14.9 to 19.6). Regarding the zirconia ceramics, the TP at $1.0 \mathrm{~mm}$ thickness, which ranged from 5.5 to 13.5 , was less than that for human dentin and enamel. These results also confirmed the ability of glass ceramics to provide a better optical match to natural teeth (29).

Zirconia translucency may be due to using zirconium oxide nanoparticles and hafnium oxide nanoparticles (colorless solid) in the new translucent zirconia composition, which may result in decreased amount of light reflection and more light transmission, because the particle size is smaller than the incident light's wavelength (30).

Zirconia's opacity can be related to two factors; the particle size of the zirconia $\left( \pm 0.4 \_\mathrm{m}\right)$ is larger than the incident wavelength of light $\left(0.1 \_\mathrm{m}\right)$ causing the light to scatter thus decreasing its transmittance, and due to the fact that there is a refractive index mismatch between its particles and the matrix causing more light to be refracted than transmitted. Thus, the less crystalline content and a refractive index close to that of the matrix cause less scattering of light, and the more translucent the material can appear (31).

Results of this study indicated that the optical properties of translucent Zirconia reinforced material (UTML KATANA zirconia), were comparable to that of the other tested Ceramic material. This is in agreement with the study performed by Baldissara et al. (9) who stated that; the translucency of the lithium disilicate glass ceramic group was significantly higher compared to all of the other zirconia groups.

The four-layer approach of the material tested in this study exhibits a significant benefit compared to the onelayer materials. Different levels of transmittance help to imitate the natural appearance and might improve the aesthetic results of monolithic restorations. A computer- aided color and transmittance measurement system might help to virtually place the restoration in the block to achieve the best possible result in the future.

Results of the current study are in agreement with UEDA et al. (26) who evaluated the transmittance of visible light through the four different layers (Enamel Layer EL, Transition Layer 1 TL1, Transition Layer 2 TL2, Body Layer BL) of a multi-coloured zirconia block (KATANA ${ }^{\mathrm{TM}}$ Zirconia Multi-Layered Disc. They concluded; this multicolored zirconia block showed four layers with different light transmittance capabilities. It might therefore be useful for enhancing the aesthetic appearance of fullcontour zirconia restorations made from this material. However, Zirconia is considered one of the most stable and physically resistant materials used in dentistry, and therefore the authors do not assume, that the slight change in translucency will influence the clinical performance of restorations fabricated from different layers of the material.

Baldissara et al. (9) stated that even the glass ceramic showed significantly higher translucency, all of the zirconia based ceramics evaluated might be considered translucent to a certain degree.

Also, results of Matsuzaki et al. (22) showed that translucent zirconia with different colors can improve translucency over conventional opaque zirconia and achieve similar colors to those of porcelain without layering porcelain. Moreover, translucent TZP has the same level of strength as opaque TZP, and the strength decreases as the thickness of veneering porcelain increases. Therefore, it is suggested that colored translucent TZP is clinically useful when used as monolithic restorations.

In agreement with the results of the current study, Harada et al. (32) measured the translucency of recently developed translucent zirconias and compared them with lithium disilicate. They concluded; at a thickness of $0.5 \mathrm{~mm}$, Katana UT was significantly more translucent than all other zirconias, and e-max CAD LT was significantly more translucent than all zirconias. At a thickness of $1.0 \mathrm{~mm}$, Prettau Anterior, Katana ST, and Katana UT were significantly more translucent than all other zirconias and less than e-max CAD LT.

Results of the current study results show similarity to results of Stawarczyk et al. (33) who found that Monolithic zirconia showed higher optical, but lower mechanical properties than conventional zirconia.

Results of Church et al. (23) were also in agreement of the current study as they found that lithium disilicate had significantly greater translucency than the zirconia materials at each thickness. In general, the translucencies of the zirconia materials were similar at each thickness.

Moreover, Carrabba et al. (24) concluded; there was an inverse relationship between strength and translucency for the materials tested. Addition of $\mathrm{Al} 2 \mathrm{O} 3$ and increasing yttria content strongly influence mechanical and optical properties of Y-TZP ceramics which will affect their clinical indications. The NT zirconia has a significant higher translucency than the other zirconia materials tested but a lower flexural strength that limits its clinical indication up to three unit FPDs.

\section{CONCLUSION}

It was concluded from this study that:

1-Monolithic zirconia materials showed statistically significant superior biaxial flexural strength values than the lithium disilicate glass ceramics. 
2-Multi-coloured zirconia block showed four layers with different light transmittance capabilities. It might therefore be useful for enhancing the aesthetic appearance of fullcontour zirconia restorations made from this material.

3-UTML katana zirconia was significantly less translucent than lithium disilicate glass ceramics.

\section{CONFLICT OF INTEREST}

The authors declare that they have no conflicts of interest.

\section{REFERENCES}

1. Conrad HJ, Seong WJ, Pesun IJ. Current ceramic materials and systems with clinical recommendations: a systematic review. J Prosthet Dent. 2007;98:389-404.

2. Rosenblum MA, Schulman A. A review of all-ceramic restorations. J Am Dent Assoc. 1997;128:297-307.

3. Guazzato M, Albakry M, Ringer SP, Swain MV. Strength, fracture toughness and microstructure of a selection of all ceramic materials. Part II. Zirconia-based dental ceramics. Dent Mater. 2004;20:449-56.

4. Beuer F, Stimmelmayr M, Gernet W, Edelhoff D, Guh JF, Naumann M. Prospective study of zirconia-based restorations: 3-year clinical results. Quintessence Int. 2010;41:631-7.

5. Fischer J, Stawarczyk B, Hammerle CH. Flexural strength of veneering ceramics for zirconia. J Dent. 2008;36:316-21.

6. Beuer F, Stimmelmayr M, Gueth JF, Edelhoff D, Naumann M. In vitro performance of full-contour zirconia single crowns. Dent Mater. 2012;28:449-56.

7. Spyropoulou PE, Giroux EC, Razzoog ME, Duff RE. Translucency of shaded zirconia core material. J Prosthet Dent. 2011;105:304-7.

8. Zhang F, Vanmeensel K, Batuk M, Hadermann J. Highly-translucent, strong and aging-resistant 3Y-TZP ceramics for dental restoration by grain boundary segregation. Acta Materialia Inc. 2015;16:215-22.

9. Baldissara P, Llukacej A, Ciocca L, Valandro FL, Scotti R. Translucency of zirconia copings made with different CAD/CAM systems. J Prosthet Dent. 2010;104:6-12.

10. Kurtulmus-Yilmaz S, Ulusoy M. Comparison of the translucency of shaded zirconia all-ceramic systems. Adv Prosthodont. 2014;6:415-22.

11. Pekkan G, Hekimoglu C. Evaluation of shear and tensile bond strength between dentin and ceramics using dualpolymerizing resin cement. J Prosthet Dent. 2009;102:242-52.

12. Addison O, Fleming GJ, Marquis PM. The effect of thermocycling on the strength of porcelain laminate veneer (PLV) materials. Dent Mater. 2003;19:291-7.

13. Timoshenko S, Woinowsky-Krieger S. Symmetrical bending of circular plates. Theory of plates and shells. 2nd ed. New York: McGraw-Hill; 87-121.

14. Johnston WM, Ma T, Kienle BH. Translucency parameter of colorants for maxillofacial prostheses. Int J Prosthodont. 1995;8:79-86.

15.ISO 6872. Dentistry-ceramic materials. Geneva: International Organization for Standardization; 2006.

16. Pieger S, Salman A, Bidra AS. Clinical outcomes of lithium disilicate single crowns and partial fixed dental prostheses: A systematic review. J Prosthet Dent. 2014;112:22-30.

17. Borges GA, Sophr AM, Goes MF, Sobrinho LC. Effect of etching and airborne particle abrasion on the microstructure of different dental ceramics. J Prosthet Dent. 2003;89:479-88.

18. Miyazaki T, Nakamura T, Matsumura H, Ban S, Kobayashi T. Current status of zirconia restorations. J Prosth Res. 2013;57:236-61.

19. Piconi C, Maccauro G. Zirconia as a ceramic biomaterial. Biomaterials. 1999; 20:1-25.

20.Kang SH, Chang J, Son HH. Flexural strength and microstructure of two lithium disilicate glass ceramics for CAD/CAM restoration in the dental clinic. Restor Dent Endod. 2013;38:134-40.

21. Johansson C, Kmet G, Rivera J, Larsson C, Vult Von Steyern P. Fracture strength of monolithic all-ceramic crowns made of high translucent yttrium oxidestabilized zirconium dioxide compared to porcelainveneered crowns and lithium disilicate crowns. Acta Odontol Scand. 2014;72:145-53.

22. Matsuzaki F, Sekine H, Honma S, Takanashi T, Furuya K, Yajima Y, et al. Translucency and flexural strength of monolithic translucent zirconia and porcelain-layered zirconia. Dent Mater J. 2015;34:910-7.

23. Church TD, Jessup JP, Guillory VL, Vandewalle KS. Translucency and strength of high-translucency monolithic zirconium oxide materials. Gen Dent. 2017;65:48-52.

24. Carrabba M, Keeling AJ, Aziz A, Vichi A, Fabian Fonzar R, Wood D, et al. Translucent zirconia in the ceramic scenario for monolithic restorations: A flexural strength and translucency comparison test. J Dent. 2017;60:70-6.

25. Corrado Piconi C, Condo SG, Kosmac T. Alumina- and zirconia-based ceramics for load-bearing applications. In: Shen JZ, Kosmač T (eds). Advanced ceramics for dentistry. Oxford: Butterworth-Heinemann; 2013. 21953.

26. Ueda K, Güth J, Erdelt K, Stimmelmayr M, Kappert H, Beuer F. Light transmittance by a multi-coloured zirconia material. J Dent Mater. 2015;34:310-4.

27. Lee YK, Cha HS, Ahn JS. Layered color of all-ceramic core and veneer ceramics. J Prosthet Dent. 2007;97:27986.

28. Denry IL. Recent advances in ceramics for dentistry. Crit Rev Oral Bio Med. 1996;7:134-43.

29. Yu B, Ahn JS, Lee YK. Measurement of translucency of tooth enamel and dentin. Acta Odontol Scand. 2009;67:57-64.

30. Heffernan MJ, Aquilino SA, Diaz-Arnold AM, Haselton DR, Stanford CM, Vargas MA. Relative translucency of six all-ceramic systems. Part II: core and veneer materials. J Prosthet Dent. 2002;88:10-5.

31. Vagkopoulou T, Koutayas SO, Koidis P, Strub JR. Zirconia indentistry: Part 1. Discovering the nature of an upcomingbioceramic. Eur J Esthet Dent. 2009;4:130-51.

32. Harada K, Raigrodski AJ, Chung KH, Flinn BD, Dogan S, Mancl LA. A comparative evaluation of the translucency of zirconias and lithium disilicate for monolithic restorations. J Prosthet Dent. 2016;116:25763.

33. Stawarczyk B, Frevert K, Ender A, Roos M, Sener B, Wimmer T. Comparison of four monolithic zirconia materials with conventional ones: Contrast ratio, grain size, four-point flexural strength and two-body wear. J Mech Behav Biomed Mater. 2016;59:128-38. 